\section{JiN}

Volume 6, No. 3

July - September 2020

www.jrmi.pk

\title{
Correlation of serum alpha fetoprotein (AFP) and tumor size of hepatocellular carcinoma (HCC) in a tertiary care hospital of Peshawar
}

\author{
Muhammad Naveed Anwar, Muhammad Khizar Hayat, Omer Nasim, Muhammad Ahmed Arsalan \\ Khan, Muhammad Shah Fahad, Zeinab Hussain
}

\section{Submitted}

August 12, 2020

Accepted

September 22, 2020

Author Information

Dr. Muhammad Naveed

Anwar

Consultant Gastroenterologist Rehman Medical Institute

Peshawar, Khyber

Pakhtunkhwa, Pakistan

(Corresponding Author)

Email:

naveed.anwar@rmi.edu.pk

Dr. Muhammad Khizar Hayat House Officer

Rehman Medical Institute

Peshawar, Khyber

Pakhtunkhwa, Pakistan

Dr. Omer Nasim

Medical Officer

Shaukat Khanam Memorial

Cancer Hospital and Research

Centre, Peshawar, Khyber

Pakhtunkhwa, Pakistan

Dr. Muhammad Ahmed

Arsalan Khan

House Officer

Rehman Medical Institute

Peshawar, Khyber

Pakhtunkhwa, Pakistan

Dr. Muhammad Shah Fahad

Medical Officer

Shaukat Khanam Memorial

Cancer Hospital and Research

Centre, Peshawar, Khyber

Pakhtunkhwa, Pakistan

\section{Zeinab Hussain}

Final Year MBBS Student

Rehman Medical College

Peshawar, Khyber

Pakhtunkhwa, Pakistan

Citation: Anwar MN, Hayat

MK, Nasim O, Khan MAA,

Fahad MS, Hussain Z.

Correlation of serum alpha

fetoprotein (AFP) and tumor

size of hepatocellular

carcinoma (HCC) in a tertiary care hospital of Peshawar. J

Rehman Med Inst. 2020 Jul-

Sep;6(3):12-5.

\begin{abstract}
Introduction: Early diagnosis of Hepatocellular Carcinoma (HCC) by imaging and biochemical tests would be valuable in controlling morbidity and mortality associated with this most common primary hepatic malignancy which is the third leading cause of global cancer-related deaths.
\end{abstract}

Objective: To determine an association between the level of serum Alpha Fetoprotein (AFP) and the size of the tumor in Hepatocellular Carcinoma (HCC)

Materials \& Methods: This cross-sectional descriptive study was conducted in Rehman Medical Institute, Peshawar, Pakistan from January 2018 till December 2019. Data were gathered from the medical records of Endoscopy Unit of Rehman Medical Institute. Patients were separated into three groups on the basis of serum AFP levels: Group I had standard levels of AFP $(<20$ IU/ml), Group II had moderately raised AFP (20-399 $\mathrm{IU} / \mathrm{ml}$ ), and Group III had significantly raised AFP $(>400 \mathrm{IU} / \mathrm{ml})$. Patients were also separated into three groups on the basis of tumor; in Group A tumor size was less than $3 \mathrm{~cm}$, in Group B it was between 3 and $5 \mathrm{~cm}$, and in Group $C$ the size was greater than $5 \mathrm{~cm}$. For categorical variables, the Chi-square and $\mathrm{Z}$ test for proportions were applied; the Wilcoxon Rank-Sum (Mann-Whitney) test was used to evaluate the variation in the two categories, and the Kruskal-Wallis Rank test was used to evaluate the difference between categories. A p value $\leq 0.05$ was taken as significant. Descriptive statistics were obtained by SPSS 24

Result: A total of 136 patients were evaluated according to AFP levels. The male to female ratio was 2.31:1. The mean presenting age was $59.36 \pm 9.85$ years while the mean tumor size was $6.93 \pm 4.39 \mathrm{~cm}$. Regarding AFP groups, there were 50(36.76\%), in Group I, 31(22.79\%) in Group II and 38(27.94\%) in Group III. As per the Child Pugh classification, Class A, B and $\mathrm{C}$ were $69.85 \%, 16.18 \%$ and $0 \%$ respectively.

Conclusion: Serum alpha fetoprotein was significantly associated with HCC tumor size. Alpha fetoprotein level can be a helpful marker to detect HCC and to differentiate between its initial and late stages. Monitoring AFP levels could be useful to diagnose recurring disease for patients with tumors that produce AFP.

Keywords: Serum Alpha Fetoprotein; Hepatocellular Carcinoma; Tumor size.

The authors declared no conflict of interest. All authors contributed substantially to the planning of research, data collection, data analysis, and write-up of the article, and agreed to be accountable for all aspects of the work.

\section{INTRODUCTION}

The most common primary malignancy of the liver is hepatocellular carcinoma (HCC), which also stands as the $3^{\text {rd }}$ leading cause of global deaths due to cancer. The major predisposing factors for HCC are viruses, particularly infections by hepatitis B (HBV) and C virus (HCV), consumption of aflatoxins, and ingestion of unclean water, particularly in rural areas. ${ }^{1} \mathrm{HBV}$ and $\mathrm{HBC}$ infections are among the leading causes of HCC as well as liver cirrhosis. ${ }^{2}$ HCC in turn is among the leading causes of death in patients who have liver cirrhosis (LC). ${ }^{3}$ The risk per annum of developing $\mathrm{HCC}$ in LC patients is about $5 \%$ (1$7 \%$ ), having a recorded incidence of 7.4 to $23 \%$ in this group of patients. Majority of the cases present with liver cirrhosis in this type of cancer.4 It has recently been seen that the more the incidence and mortality of $\mathrm{HCC}$, the greater it is likely to reflect $\mathrm{HCV}$ infection. ${ }^{4}$ Estimated incidence in Pakistan is $8 / 100,000$ per year. ${ }^{5}$ As $\mathrm{HCC}$ is highly linked to chronic liver disease such as cirrhosis, people having liver cirrhosis should be routinely checked with imaging techniques such as ultrasound and computed tomography, in conjunction with verification of serum AFP. ${ }^{6-8}$

Alpha-fetoprotein is a glycoprotein consisting of 591 amino acids, and it has a half-life of 5 to 7 days. Although it is made by the yolk sac of the fetus (after $7^{\text {th }}$ week of gestation), fetal liver and gut, raised levels of AFP are linked with HCC in the suitable clinical setting. ${ }^{9}$ Raised level of alphafetoprotein were detected in $60-70 \%$ of $\mathrm{HCC}$ cases; however, there are other reasons for its raised numbers, including cirrhosis, lung carcinoma, biliary carcinoma, gastric carcinoma, pancreatic carcinoma, testis teratocarcinoma, spherocytosis and tyrosinemia. ${ }^{10}$ Sharieff et al showed AFP to be raised in $76 \%$ of $\mathrm{HCC}$ patients. ${ }^{11}$ The alpha-fetoprotein's sensitivity and specificity are dependent on the cut-off values chosen; the cut-off value of $20 \mathrm{ng} / \mathrm{ml}$ has a sensitivity of about $60 \%$ and a favorable predictive value between $9 \%$ and $50 \%$. Ultrasonography quality as a screening instrument relies upon the expertise and equipment of the observer. 
The sensitivity of ultrasound is higher than $60 \%$ and its specificity is $90 \% .^{12}$

The mortality rate of HCC is more elevated than ought to be the case. This is because it does not display obvious features until too late, and when detected earlier on, it has better chances of healing. This is one of the primary reasons why the development of detection and diagnostic instruments must be prioritized to reverse its mortality and morbidity. ${ }^{13}$

Routine screening for cases at high risk is required for achieving this aim. Regular screening methods include indicators such as the Child Pugh score (which determines prognosis for chronic hepatic diseases via concentrations of serumbilirubin and albumin, prothrombin time, levels of ascites and liver encephalopathy); or the Barcelona clinic for liver cancer (BCLC) stage (a staging system which evaluates hepatic carcinoma on the basis of amount and size of tumors, health status of the individual and hepatic function, in regards to the Child Pugh Score). Such screening techniques also include imaging (such as ultrasonography, MRI or computed tomography) and relevant tests for serum tumor markers. ${ }^{14}$

Tumor markers are made either by cells that have undergone neoplasia, or by the body responding to their invasion, which lets us determine the cancer's prognosis or the treatment's efficiency. Alpha Feto Protein (AFP) is the most commonly used tumor marker for hepatocellular carcinoma. ${ }^{15}$

Individuals with levels of this marker over $20 \mathrm{IU} / \mathrm{ml}$ must be examined closely because higher levels are usually associated with liver cancer. Other neoplasia may increase levels of AFP, as may other hepatic diseases, which implies that serum AFP may not be a reliable diagnostic tool. A study by Rehman KU et $\mathrm{al}^{16}$ determined a significant correlation in the level of serum alpha fetoprotein and size of tumors in HCC $(r=0.668)$. Abbasi et $\mathrm{al}^{17}$ previously showed significant association in levels of serum AFP with tumor size in HCC $(\mathrm{r}=0.472,0.0001)$. In contrast Sharieff et $\mathrm{al}^{11}$ reported no significant correlation between the tumor size and the level of alpha fetoprotein ( $\mathrm{r}=-$ $0.155 ; p=0.129)$. In view of these contradictory results, we decided to conduct this study with the main objective of establishing the association between serum AFP levels and size of tumor of hepatocellular carcinoma. Our research aimed to compare the importance of serum AFP, with the tumor size determined by ultrasound, CT and software tomography.

\section{MATERIALS \& METHODS}

This cross-sectional analytical study was carried out in Rehman Medical Institute (RMI), Peshawar, Pakistan from January 2018 to December 2019. Data were gathered from the medical records of Endoscopy Unit of RMI. Demographic details including age, sex, and address were recorded. Extensive examinations had been done, and thorough histories taken. Complete blood count, liver function test, A/G ratio, serum Albumin, HBsAg, anti $\mathrm{HCV}$, AFP, ultrasonography whole abdomen and CT-scan Abdomen, were carried out. On the grounds of Alpha fetoprotein levels, patients were separated into three groups; Group I had standard AFP levels $(<20 \mathrm{IU} / \mathrm{ml})$, Group II had moderately raised AFP (20-399 IU/ml), and Group III had significantly raised AFP (> $400 \mathrm{IU} / \mathrm{ml}$ ). Patients were also separated into three categories on the basis of tumor; in Group A tumor size was $<3 \mathrm{~cm}$, in Group B it was between 3 to $5 \mathrm{~cm}$ and in Group $\mathrm{C}$ the size was $>5 \mathrm{~cm}$.

Mean and Standard Deviation were taken as indices of centrality and dispersion of the distribution. For categorical variables, the Chi-square and $\mathrm{Z}$ test for proportions were used; the Wilcoxon Rank-Sum (Mann-Whitney) test was used to evaluate the variation between the two categories, and the Kruskal-Wallis Rank Test to evaluate the differences among categories. A p $\leq 0.05$ was taken to be significant. Descriptive statistics were acquired for the variables where applicable, using SPSS 24.

\section{RESULTS}

Total 136 patients were evaluated according to AFP levels. Patients with AFP levels (ng/dl) $\leq 20(36.76 \%)$, in the range 21 $399(22.79 \%)$ and $\geq 400(27.94 \%)$. The male/female ratio is $2.31: 1$ with males $(69.85 \%)$ and females $(30.15 \%)$. The mean presenting age is $59.36 \pm 9.85$ years while the mean tumor size was $6.93 \pm 4.39 \mathrm{~cm}$. Classifying data as per Child Pugh classification, Class A, B and C were $69.85 \%, 16.18 \%$ and $0 \%$ respectively. Basic characteristics of the participants are displayed in Table 1, classified according to their AFP levels.

Table 1: Basic Characteristics of Hepatocellular Carcinoma Patients (n=136).

\begin{tabular}{|c|c|c|c|c|c|}
\hline \multirow{2}{*}{ Variables } & \multirow{2}{*}{$f(\%)$} & \multicolumn{3}{|c|}{ Alpha Fetoprotein Levels* (ng/dl) } & \multirow{3}{*}{ p-value } \\
\hline & & \multirow{2}{*}{$\begin{array}{c}\leq 20 \\
50(36.76)\end{array}$} & \multirow{2}{*}{$\begin{array}{c}21-399 \\
31(22.79)\end{array}$} & \multirow{2}{*}{$\begin{array}{c}\geq 400 \\
38(27.94)\end{array}$} & \\
\hline \multicolumn{2}{|l|}{ AFP Groups } & & & & \\
\hline \multicolumn{5}{|l|}{ Gender } & \multirow{3}{*}{0.564} \\
\hline Male & $95(69.85)$ & 36 & 19 & 27 & \\
\hline Female & $41(30.15)$ & 14 & 12 & 11 & \\
\hline \multicolumn{5}{|l|}{ Age* (years) } & \multirow{3}{*}{0.457} \\
\hline$<=40$ & $04(2.94)$ & 02 & 0 & 02 & \\
\hline$>40$ & $131(96.32)$ & 48 & 31 & 37 & \\
\hline \multicolumn{5}{|l|}{ Etiology* } & \multirow{4}{*}{0.264} \\
\hline HBV & $11(8.09)$ & 04 & 02 & 05 & \\
\hline $\mathrm{HCV}$ & $92(67.65)$ & 37 & 27 & 28 & \\
\hline Negative B\&C & $15(11.03)$ & 09 & 01 & 05 & \\
\hline \multicolumn{5}{|l|}{ Child-Pugh class* } & \multirow{4}{*}{0.072} \\
\hline A & $95(69.85)$ & 44 & 25 & 26 & \\
\hline $\mathrm{B}$ & $22(16.18)$ & 05 & 06 & 11 & \\
\hline $\mathrm{C}$ & 0 & 0 & 0 & 0 & \\
\hline \multicolumn{5}{|l|}{ Tumor Size* $(\mathrm{cm})$} & \multirow{4}{*}{0.021} \\
\hline$<3 \mathrm{~cm}$ & $17(12.50)$ & 06 & 08 & 03 & \\
\hline $3-5 \mathrm{~cm}$ & 35 (25.74) & 18 & 10 & 07 & \\
\hline$>5 \mathrm{~cm}$ & $63(46.32)$ & 24 & 11 & 28 & \\
\hline
\end{tabular}


Table 2 shows the blood and serum parameters mean according to the AFP ranges and their significance according to the Kruskal-Wallis rank test. All the samples are not significant except for Bilirubin $(\mathrm{p}=0.005)$. The highest mean $\mathrm{Hb}$ reading was recorded in the AFP range 21-399 (12.81). A similar trend was observed in the ALT reading (77.2). In the AFP $\leq 20$, platelets (205.8) and albumin (3.55) showed higher readings in comparison to the other ranges. AFP $\geq 400$ showed a higher bilirubin (1.21) along with ALP (216.8).

Table 2: Blood Parameters Classified According to AFP Ranges

\begin{tabular}{|l|c|c|c|c|}
\hline \multicolumn{1}{|c|}{ Parameters } & $\begin{array}{c}\text { AFP } \leq \mathbf{2 0} \\
(\mathbf{5 0})\end{array}$ & $\begin{array}{c}\text { AFP 21-399 } \\
(\mathbf{3 1})\end{array}$ & $\begin{array}{c}\text { AFP } \geq 400 \\
(38)\end{array}$ & $\begin{array}{c}\text { Kruskal-Wallis } \\
\text { Rank Test }\end{array}$ \\
\hline HB $(\mathrm{g} / \mathrm{dl})$ & $12.38 \pm 2.76$ & $12.81 \pm 1.96$ & $12.58 \pm 2.39$ & 0.806 \\
\hline Platelets $\left(10^{3} / \mathrm{\mu L}\right)$ & $205.8 \pm 143.3$ & $145.8 \pm 92.8$ & $182.0 \pm 100.4$ & 0.105 \\
\hline Albumin $(\mathrm{g} / \mathrm{dl})$ & $3.55 \pm 0.72$ & $3.47 \pm 0.70$ & $3.47 \pm 0.44$ & 0.546 \\
\hline Bilirubin $(\mathrm{mg} / \mathrm{dl})$ & $0.88 \pm 0.50$ & $0.87 \pm 0.48$ & $1.21 \pm 0.61$ & 0.005 \\
\hline ALT $(\mathrm{U} / \mathrm{L})$ & $57.1 \pm 41.9$ & $77.2 \pm 74.0$ & $65.5 \pm 41.3$ & 0.570 \\
\hline ALP $(\mathrm{U} / \mathrm{L})$ & $194.7 \pm 123.5$ & $179.0 \pm 103.8$ & $216.8 \pm 120.0$ & 0.305 \\
\hline \multicolumn{5}{|c}{ Significance levels $\leq 0.05$}
\end{tabular}

Table 3 classifies the blood parameters according to Mean Tumor Diameter (MTD), which is subdivided by the AFP range. No readings are found to be statistically significant apart from the MTD $>5.0 \mathrm{~cm}$ and AFP $>100$ bilirubin comparison (0.009). The AFP ranges classified according to nodule number is also statistically not significant $(\mathrm{p}>0.05)$. All the parameters mean were seen to generally increase as the MTD increased in the AFP $\leq 100$ range. For AFP $>100$, a similar trend was observed with the exception of platelets, albumin and ALP.

Table 3: Blood parameters classified according to Mean Tumor Diameter, Nodule Number, and AFP levels (n=136).

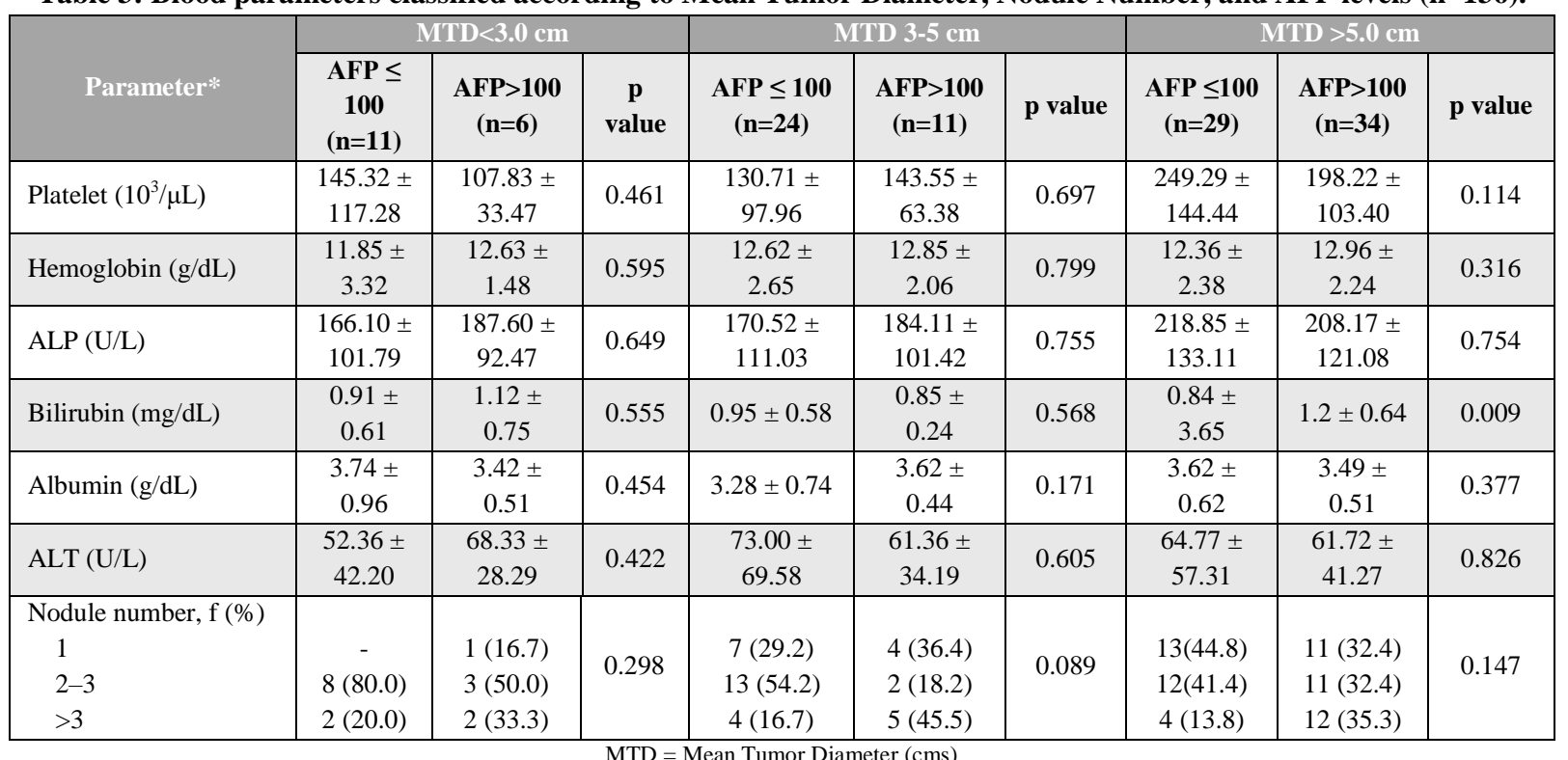

\section{DISCUSSION}

To the extent of our knowledge, this study is the first of its kind that correlated serum alpha fetoprotein levels with the tumor size in cases of HCC in this part of Pakistan. In this study, AFP positivity is checked to analyze its correlation to tumor size. The study showed that patients with a raised alpha fetoprotein level were found to correlate to the HCC tumor size. This study also exhibited that mild increased bilirubin was significantly associated with increase in Mean Tumor Diameter (MTD), especially for the larger size tumors. Overall, our study revealed $50.7 \%$ AFP positivity in patients of hepatocellular carcinoma. Alpha fetoprotein positivity in HBV positive HCC cases was $63.6 \%$. and in HCV positive HCC cases it was $59.7 \%$. Furthermore, when quantitative degrees of alpha fetoprotein were assessed, the cases with HCV showed markedly raised AFP than patients with HBV alone HCC cases.
Tangkijvanich $\mathrm{P}$ et $\mathrm{al}^{18}$ did a study on clinical characteristics of hepatocellular carcinoma and found that 76 (24.6\%) had AFP level <20 ng / ml, 78 (25.2\%) had levels of 20-399 $\mathrm{ng} / \mathrm{ml}$ and 155 patients $(50.2 \%)$ had levels equal or $>400 \mathrm{ng} / \mathrm{ml}$. In our study we found that $50(36.7 \%)$ had AFP level $<20 \mathrm{ng} / \mathrm{ml}, 31$ $(22.7 \%)$ had levels between $20-399 \mathrm{ng} / \mathrm{ml}$, and 38 (27.94\%) had levels equal or greater than $400 \mathrm{ng} / \mathrm{ml}$. In the same study it was seen that HCC patients having raised Alpha fetoprotein levels were inclined to have larger tumor measurements, which was parallel to our result.

Another study determined the alpha fetoprotein levels as an independent predictor of tumor size. ${ }^{19}$ Abbasi A et $\mathrm{al}^{17}$ concluded in the study that serum Alpha fetoprotein has significant association with tumor size. In our study we also 
found that the tumor marker level is significantly corresponding with the tumor size of $\mathrm{HCC}$ patients.

Reportedly, increased platelets were found to be associated with an increase in mean tumor diameter (MTD), especially for the larger size tumors. ${ }^{20}$ In our study bilirubin was associated with increase in mean tumor diameter (MTD), especially for the larger size tumors in patients of HCC. Shabbir $\mathrm{K}$ et $\mathrm{al}^{21}$ and Sharieff et $\mathrm{al}^{11}$ concluded in their studies that there was not a correlation between the alpha fetoprotein levels and the tumor size, which was exactly contradictory to our results.

\section{CONCLUSION}

The study conducted shows serum alpha fetoprotein has a significant association with tumor size. Alpha fetoprotein level can be a helpful marker to detect HCC and to discern between its initial and late stages, on which grounds the appropriate treatment plan can be decided. Monitoring AFP levels could be useful in order to diagnose recurring disease, though this is mostly limited to patients with tumors that produce AFP.

\section{REFERENCES}

1. Caldwell S, Park SH. The epidemiology of hepatocellular cancer: from the perspectives of public health problem to tumor biology. J Gastroenterol. 2009;44:96-101.

2. Zhang BH, Yang BH, Tang ZY. Randomized controlled trial of screening for hepatocellular carcinoma. J Cancer Res Clin Oncol. 2004;130:417-22.

3. El-Serag HB, Davila JA, Petersen NJ, McGlynn KA. The continuing increase in the incidence of hepatocellular carcinoma in the United States: an update. Ann Intern Med. 2003;139:81723.

4. Aguayo A, Patt YZ. Liver cancer. Clin Liver Dis. 2001;5:479-507.

5. Abdul Mujeeb S, Jamal Q, Khanani R, Iqbal N, Kaher S. Prevalence of hepatitis B surface antigen and $\mathrm{HCV}$ antibodies in hepatocellular carcinoma cases in Karachi, Pakistan. Trop Doct. 1997;27:45-6.

6. Kubo Y, Okuda K, Musha H, Nakashima T. Detection of hepatocellular carcinoma during a clinical follow-up of chronic liver disease: observation in 31 patients. Gastroenterology. 1978;74:578-82.

7. Oka H, Kurioka N, Kim K, Kanno T, Kuroki T, Mizoguchi Y, et al. Prospective study of early detection of hepatocellular carcinoma in patients with cirrhosis. Hepatology. 1990;12:680-7.

8. Shinagawa $T$, Ohto $M$, Kimura $K$, Tsunetomi S, Morita M, Saisho H, et al. Diagnosis and clinical features of small hepatocellular carcinoma with emphasis on the utility of real-time ultrasonography: a study in 51 patients. Gastroenterology. 1984;86:495-502.
9. Aoyagi Y, Suzuki Y, Igarashi K, Saitoh A, Oguro M, Yokota $\mathrm{T}$, et al. Carbohydrate structures of human alphafetoprotein of patients with hepatocellular carcinoma: presence of fucosylated and non-fucosylated triantennary glycans. $\mathrm{Br} \mathrm{J}$ Cancer. 1993;67:486-92.

10. Mizejewski GJ. Levels of alphafetoprotein during pregnancy and early infancy in normal and disease states. Obstet Gynecol Surv. 2003;58:804-26.

11. Sharieff S, Burney I, Salam A, Siddiqui T. Lack of correlation between aipha fetoprotein and tumor size in hepatocellular carcinoma. J Pak Med Assoc. 2001;51:123-4.

12. Daniele B, Bencivenga A, Megna AS, Tinessa V. Alpha-fetoprotein and ultrasonography screening for hepatoculular carcinoma. Gastroenterol. 2004;127:S108-12.

13. Davis GL, Dempster J, Meler JD, Orr DW, Walberg MW, Brown B, et al. Hepatocellular carcinoma: Management of an increasingly common problem. Proc (Bayl Univ Med Cent). 2008;21(3):266-80.

14. Chedid F, Kruel CR, Pinto MA, Grezzana-filho TJ, Leipnitz I, Kruel $\mathrm{CDP}$, et al. Hepatocellular carcinoma: diagnosis and operative management. ABCD. Arquivos Brasileiros de Cirurgia Digestiva (São Paulo). 2017;30(4):272-8.

15. Patil M, Sheth KA, Adarsh CK. Elevated alpha fetoprotein, no hepatocellular carcinoma. J Clin Exp Hepatol. 2013; 3(2):162-4

16. Rehman KU, Samiullah M, Sharif S, Farhat S. Hepatocellular carcinoma; correlation of serum alpha fetoprotein and tumor size. Professional Med J. 2016;23(2):209-212.

17. Abbasi A, Bhutto AR, Butt N, Munir SM. Corelation of serum alpha fetoprotein and tumor size in hepatocellular carcinoma. J Pak Med Assoc. 2012 Jan;62(1):33-6.

18. Tangkijvanich $\mathrm{P}$, Anukulkarnkusol $\mathrm{N}$ Suwangool $P$, Lertmaharit $S$, Hanvivatvong $\mathrm{O}$, Kullavanijaya $\mathrm{P}$, et al. Clinical characteristics and prognosis of hepatocellular carcinoma: Analysis based on serum alpha-fetoprotein levels. J Clin Gastroenterol. 2000;31(4):302-8.

19. Bai DS, Zhang C, Chen P, Jin SJ, Jiang GQ. The prognostic correlation of AFP level at diagnosis with pathological grade, progression, and survival of patients with hepatocellular carcinoma. Sci Rep. [Internet]. Springer US; 2017;7(1):1-9. Available from: http://dx.doi.org/10.1038/s41598-01712834-1

20. Carr BI, Akkiz H, Üsküdar O, Yalçın K, Guerra V, Kuran S, et al. HCC with lowand normal-serum alpha-fetoprotein levels. Clin Pract (Lond). 2018;15(1):453-64.

21. Sahbbir K, Shehzad A, Naqvi M, Khalid M, Zia N, Haider E, et al. Association of serum alpha fetoprotein (AFP) levels with size of hepatocellular carcinoma. PAFMJ. 2019;69(1):71-5. Retrieved from https://www.pafmj.org/index.php/PAFM J/article/view/2499 